\title{
Finding an effective way to create learning environments for didactic courses in a virtual classroom setting
}

\author{
Santosh Kumar \\ College of Pharmacy, University of Tennessee Health Science Center, Memphis, United States
}

\author{
Keywords \\ COVID-19 \\ Didactic teaching \\ Interactive session \\ Virtual classroom \\ Zoom webinar \\ Correspondence \\ Santosh Kumar \\ University of Tennessee \\ Health Science Center \\ 881 Madison Ave \\ Memphis \\ TN 38163 \\ United States \\ ksantosh@uthsc.edu
}

\begin{abstract}
Background: The COVID-19 pandemic forced college administrators to do virtual classes using Zoom webinars during the autumn of 2021. The study objective is to examine the relative efficacy of interactive vs non-interactive Zoom webinars in virtual classrooms during the COVID-19 era. Methods: These two modes of live Zoom webinars were used for Year 1 Pharmacy students. Two surveys were conducted among students for general feedback on teaching and their preferred type of virtual learning. Results: Amongst the 177 students present, 87 (49\%) responded to the first survey, of whom $20(23 \%)$ provided their feedback about the Zoom webinar. Amongst these responders, a relatively higher number of students preferred interactive Zoom webinars with student panellists. Also, of the 177 students, $118(66.7 \%)$ students responded to the second survey on the mode of live Zoom webinars. Amongst the respondents, around 88-99 (74-84\%) agreed or strongly agreed that a live Zoom webinar with interactive sessions is more effective than non-interactive sessions. Additionally, $73(62 \%)$ of the respondents preferred five to ten students in the panel. Furthermore, the survey analysis suggested that the effectiveness of interactive sessions is the same irrespective of the instructors. Conclusion: The results concluded that the interactive live Zoom webinar with 5-10 student panellists is effective in creating a learning environment in virtual didactic courses.
\end{abstract}

\section{Introduction}

During the COVID-19 era, all the didactic lectures occurred in a virtual classroom, using Zoom webinars in particular (Camargo et al., 2020). Zoom webinar classrooms could be 1) live with no access to student cameras, 2) live with all cameras on, and 3) live with the freedom for students to keep their cameras on or off. These live Zoom lecture modes have advantages and disadvantages (Warner, 2020). For example, some students are not comfortable nor ready to have their cameras on. Their learning capability is reduced due to the consciousness of being seen on camera and the invasion of privacy. However, when no cameras are on, it is hard to determine students' engagement. Although several methods have been employed to address this issue, no efficacious approach has been yet established (Pitts, 2020). In this pilot study, the objective is to examine the relative effectiveness of interactive vs non-interactive live Zoom lectures in a virtual classroom.

\section{Methods \\ Modes of virtual learning}

The study was performed at the University of Tennessee Health Science Center (UTHSC) College of Pharmacy. It was approved by the UTHSC Institutional Review Board (IRB). The instructor taught two courses to Year 1 Pharmacy (P1) students (Class of 2024). The P1 consisted of 177 students (64\% females and 36\% males). The student demography is as follows: Asian (18\%), Black or African American (21\%), White (56\%), Hispanic or Latinos (4.5\%), and others (0.5\%). The instructor taught 14 of the 30 lectures in Fundamentals of Drug Action (FDA) and seven of the 37 lectures in Biochemistry. In FDA, the instructor created a panel of 12-13 students for each lecture so that every student gets one opportunity to interact with the instructor (117 students and 14 lectures). The interaction with the student panellists included a general introduction of the students before the class began and then discussion 
and question/answer sessions. In Biochemistry, the instructor performed a standard live Zoom webinar in which no students interacted with the instructor. Other instructors in these two courses used non-interactive live Zoom webinars.

\section{Students survey}

In the middle of the term, the students provided anonymous written general feedback using the Zoom chat. This feedback covered several areas, including the instructor's knowledge in the subject, effective communication, clarity of slides, amounts of materials presented, staying on time, etc. At the end of the term, the instructor conducted an anonymous survey that consisted of four questions related to the effectiveness of the interactive live Zoom webinar using student panellists (Figure 1). It explored the classroom learning effectiveness of the following: A) live Zoom webinars compared to recorded lectures; B) interactive sessions with panellists compared to non-interactive sessions in the same course given by other instructors; C) interactive sessions with panellists compared to noninteractive sessions given by the same instructor in a different course. The survey also recorded the number of student panellists appropriate for effective learning in interactive sessions (D).

\section{Statistical analysis}

The survey data from the interactive Zoom webinar, presented in Figure $1 \mathrm{~A}-\mathrm{C}$, were analysed using a Likert scale, where each option was given a ranking score: strongly disagree (1), disagree (2), neither agree nor disagree (3), agree (4), and strongly agree (5). Furthermore, one-way ANOVA with Tukey's multiple comparison test was used to calculate the statistical significance of questions A-C. The data were analysed using Graph-Pad Prism version 7.0 (GraphPad Software, La Jolla, CA, USA). A $p$-value $\leq 0.05$ was considered statistically significant.

\section{Results}

Of the 177 students present in the FDA class, 87 (49\%) responded to the written general feedback and expressed their opinion about the instructor's teaching effectiveness. Out of the 87 students who responded, 20 (23\%) provided their feedback about the live Zoom webinar formats and their efficacy on learning (Table I). Of the 20 students, 6 (30\%) favoured Zoom webinars, while 5 (25\%) wished they had in-person learning. Furthermore, a relatively higher number of students, 9 of $20(45 \%)$, preferred interactive Zoom webinars with student panellists (Table I). The results suggest that live Zoom interactions are paramount for students' effective learning when in-person learning is not possible.

Table I: Mid-term feedback on the effectiveness of instructor's teaching

\begin{tabular}{|c|c|}
\hline $\begin{array}{l}\text { Modes of } \\
\text { classes }\end{array}$ & Feedback from students (verbatim related to preference on Zoom webinar) \\
\hline $\begin{array}{l}\text { In favour of } \\
\text { webinar }\end{array}$ & $\begin{array}{l}\text { - I definitely prefer the webinar format since I don't get distracted by numerous comments coming in from } \\
\text { students; they can be annoying at times in other classes. } \\
\text { - I like the webinar format. } \\
\text { - Webinar is great. } \\
\text { - I prefer the webinars. } \\
\text { - I like the webinars better. } \\
\text { - I like webinar because I can focus better without seeing everyone in the camera. } \\
\text { - I personally prefer webinar over meetings. }\end{array}$ \\
\hline $\begin{array}{l}\text { In favour of Zoom } \\
\text { with student } \\
\text { panellists }\end{array}$ & $\begin{array}{l}\text { - The way he has approached to this new challenging platform is just amazing. He has always created a positive } \\
\text { environment for the students and I personally have never felt that I was on Zoom. It felt more as if we were face } \\
\text { to face in class. } \\
\text { - Zoom meetings are much more preferred than webinars. } \\
\text { - I enjoy the webinars with rotating panellist it keeps people engaged. } \\
\text { - I like how he selects a group of students for each class. } \\
\text { - I also prefer meetings but the webinar with panels is neat as well. } \\
\text { - I do like the Zoom meetings better than the webinars because I feel like it is easier to interact with the instructor. } \\
\text { - I think he has done a great job teaching over Zoom webinar. I like the format of the class. } \\
\text { - I enjoy the active learner participants in FDA and think that's a really good method of keeping us engage. }\end{array}$ \\
\hline $\begin{array}{l}\text { In favour of } \\
\text { classroom } \\
\text { meeting }\end{array}$ & $\begin{array}{l}\text { - I like the meetings way better! its more human interaction. } \\
\text { - I like meetings better than webinar but sometimes when people ask questions in chat it is very distracting. } \\
\text { - I wish there was more of a mix between webinar and meetings. I prefer the meetings as it makes you feel more } \\
\text { engaged in the lecture. I think Zoom learning makes courses more difficult. } \\
\text { - Zoom fatigue is becoming more and more a thing and distractions are plentiful. It is easy to get side-tracked on } \\
\text { something besides the lecture. I hope to go back into classrooms soon. } \\
\text { - I like the meetings better than webinars. }\end{array}$ \\
\hline
\end{tabular}


In a separate survey, out of 177 students, 118 (66.7\%) responded to the survey questions, of whom 99 (84\%) agreed or strongly agreed that live Zoom webinars were more effective than recorded lectures (Figure 1A). Furthermore, 94 (79\%) students agreed or strongly agreed that interactive sessions using panellists improved their learning experience compared to noninteractive sessions of the same course (Figure 1B). Similarly, 88 (74\%) students agreed or strongly agreed that interactive sessions also helped their learning experience compared to non-interactive sessions given by the same instructor (Figure 1C). Finally, 74 (63\%) students indicated that 5-10 panellists are appropriate for efficient interactive sessions, while only 30 (25\%) students found that the adequate number is $10-15$ panellists (Figure 1D).

Furthermore, the statistical analysis of the survey in Figure $1 \mathrm{~A}-\mathrm{C}$ showed that the effectiveness of live Zoom webinars ranked significantly higher (Figure 1E: Q1, $4.39 \pm 0.85)$ than the other survey questions on the effectiveness of interactive sessions (Figure 1E: Q2, $4.10 \pm 0.92$ and Q3, 4.03 \pm 0.90$)$. Although interactive sessions were highly effective, there was no significant difference in interactive sessions when given by the same instructor in different courses or different instructors in the same course (Figure 1: Q2, 4.10 \pm 0.92 and Q3, 4.03 \pm 0.90$)$.
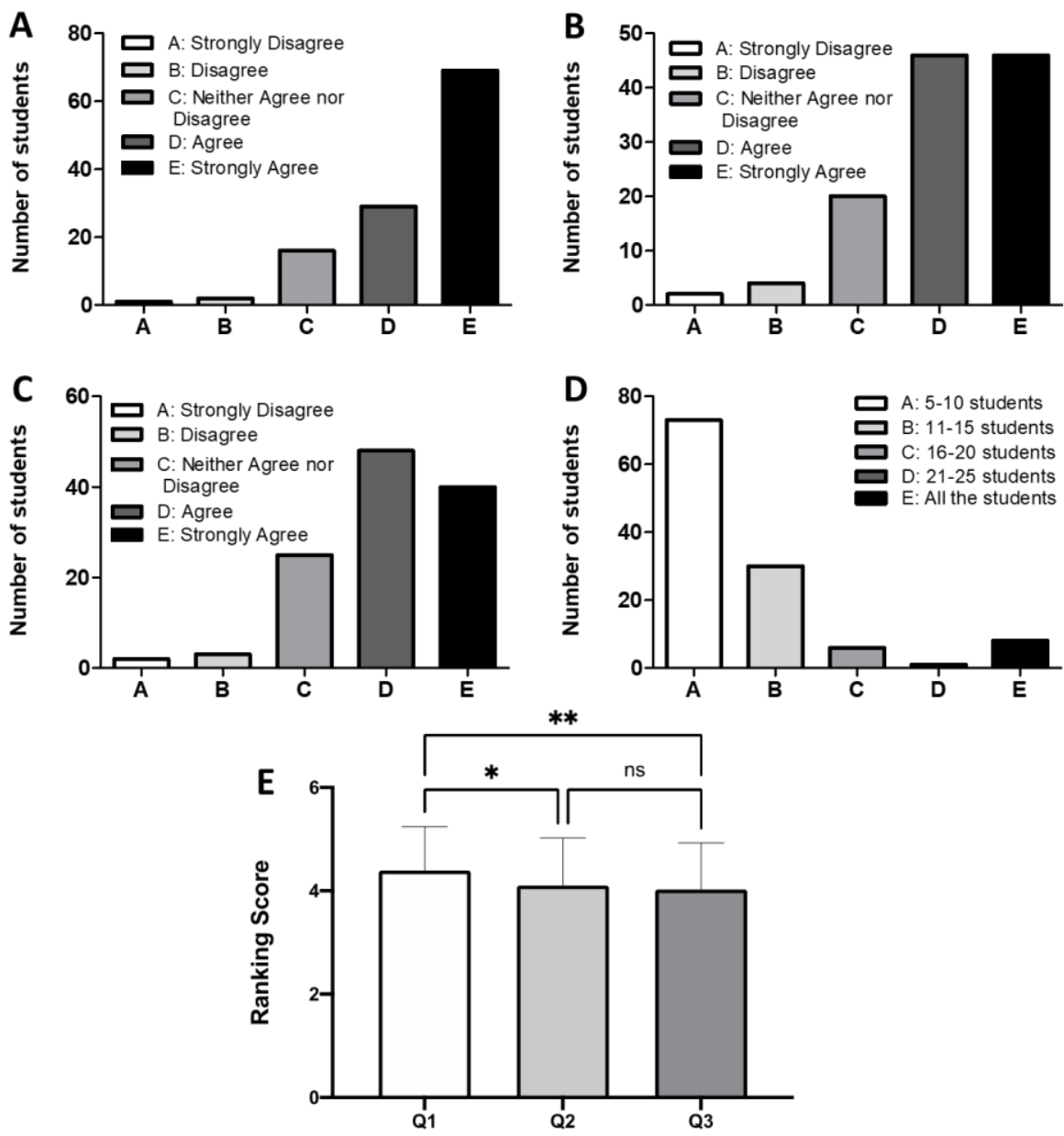

\begin{abstract}
A: Compared to recorded lectures, the live Zoom webinar enhances the classroom experience and overall learning in the course; B: Compared to non-interactive sessions in the same course, the interactive sessions with panellists helped to increase the overall classroom learning in the live Zoom webinar; C: Compared to non-interactive sessions by the same instructor in different courses, the interactive sessions with panellists helped to increase the overall classroom learning in the live Zoom webinar; D: The number of panellists in the interactive sessions should be limited to: The options for each question and their response is provided in the figure. Out of 177 students, 118 responded to these survey questions. The actual number of student respondents are present in the $y$-axis of each figure. E: The data in Fig. A-C (questions 1-3) were analysed using a Likert scale by ranking survey options A-E with scores 1-5, respectively. One-way ANOVA with Tukey's multiple comparison test was used to calculate the statistical significance at $p \leq 0.05$.
\end{abstract}

Figure 1: P1 student surveys on modes of effective learning in virtual classroom with interactive Zoom webinars 


\section{Discussion}

The study concluded that live Zoom webinars using interactive sessions with five to ten student panellists are the most effective learning method in virtual didactic courses. This study is the first to use an interactive session with a fixed number of student panellists, reporting the preference for effective learning that could be applied in other courses. It also suggests that interactive sessions are effective in classroom learning, irrespective of the instructors who gave the interactive sessions. Thus, interactive sessions using five to ten panellists can be implemented by other instructors to create an effective learning environment in Zoom webinars. The effectiveness of interactive sessions was also consistent with the high class-average grades students obtained in the course given by the same instructor (average grades of $\sim 90 \%$ in interactive vs around $85 \%$ in non-interactive sessions). Several reasons explain why students do well in class, such as instructors' knowledge of the course, lecture delivery, active learning sessions, and ease or difficulty of the questions (Love et al., 1982). However, in this study, it can be noted that the average students' grades were relatively high in the exams related to the lectures that were given using interactive session compared to non-interactive session.

In virtual classroom settings, interactive sessions appear to help engage and learn relatively more students. While some instructors prefer to do noninteractive sessions, others favour interactive sessions (Pitts, 2020). However, interactive sessions with a small number of panellists, as in this study, helps track students' body language and eye contact and adjust the delivery based on their engagements. Student panellists were actively involved in discussion and question/answer sessions, which likely kept other students who were not part of the panel engaged in the Zoom webinar. Although it has been suggested to redefine academic freedom, every instructor has the academic freedom to teach didactic courses the way that they see helps student learning (Woods et al., 2016). It is, however, important that instructors consider and examine all the modes of virtual learning and find an appropriate one that works for them. In pharmacy education, optimizing the classroom experience for effective learning, including various forms of active learning, is essential to improve teaching scholarship (Lampkin et al., 2015; Wilson et al., 2017; Hopper \& Brake, 2018; Wilson et al., 2019). Moreover, COVID-19 and virtual learning have accelerated a need for active learning (Ambroziak et al., 2018). Virtual learning may likely become the principal mode of lecture delivery for some colleges or courses. It is, therefore, also important to maintain the wellbeing of students, which have declined during virtual classes (Browning et al., 2021). In part, this can be done by implementing intervention strategies as performed recently by basic science researchers (Kumar et al., 2020).

\section{Acknowledgements:}

The author acknowledges P1 students at the College of Pharmacy, University of Tennessee Health Science Center, for their participation in the survey.

\section{Reference}

Ambroziak, K., Ibrahim, N., Marshall, V. D., \& Kelling, S. E. (2018). Virtual simulation to personalize student learning in a required pharmacy course. Curr Pharm Teach Learn, 10(6), 750-756. https://doi.org/10.1016/j.cptl.2018.03.017

Browning, M., Larson, L. R., Sharaievska, I., Rigolon, A., McAnirlin, O., Mullenbach, L., et al. (2021). Psychological impacts from COVID-19 among university students: Risk factors across seven states in the United States. PLoS One, 16(1), e0245327.

https://doi.org/10.1371/journal.pone.0245327

Camargo, C. P., Tempski, P. Z., Busnardo, F. F., Martins, M. A., \& Gemperli, R. (2020). Online learning and COVID-19: a meta-synthesis analysis. Clinics (Sao Paulo), 75, e2286. https://doi.org/10.6061/clinics/2020/e2286

Hopper, M. K., \& Brake, D. A. (2018). Student engagement and higher order skill proficiency: a comparison of traditional didactic and renewed integrated active learning curricula. Adv Physiol Educ, 42(4), 685-692. https://doi.org/10.1152/advan.00149.2018

Kumar, S., Kodidela, S., Kumar, A., Gerth, K., \& Zhi, K. (2020). Intervention and Improved Well-Being of Basic Science Researchers During the COVID 19 Era: A Case Study. Front Psychol, 11, 574712.

https://doi.org/10.3389/fpsyg.2020.574712

Lampkin, S. J., Collins, C., Danison, R., \& Lewis, M. (2015). Active learning through a debate series in a first-year pharmacy self-care course. Am J Pharm Educ, 79(2), 25. https://doi.org/10.5688/ajpe79225

Love, D. W., Heller, L. E., \& Parker, P. F. (1982). The use of student evaluations in examining clinical teaching in pharmacy. Drug Intell Clin Pharm, 16(10), 759-764. https://doi.org/10.1177/106002808201601010

Pitts, V. (October 23, 2020). Teaching into the Abyss: Addressing Students' Camera Usage (or Lack Thereof!) in Zoom. Available at: https://otl.du.edu/teaching-into-theabyss-addressing-students-camera-usage-or-lack-thereof-inzoom/

Warner, J. (August 19, 2020). Student Zoom Expectations: Camera On, Please!, Available at: https://blog.smu.edu/itconnect/2020/08/19/student-zoomexpectations-camera-on/ 
Wilson, J. A., Pegram, A. H., Battise, D. M., \& Robinson, A. M. (2017). Traditional lecture versus jigsaw learning method for teaching Medication Therapy Management (MTM) core elements. Curr Pharm Teach Learn, 9(6), 1151-1159. https://doi.org/10.1016/j.cptl.2017.07.028

Wilson, J. A., Waghel, R. C., \& Dinkins, M. M. (2019). Flipped classroom versus a didactic method with active learning in a modified team-based learning self-care pharmacotherapy course. Curr Pharm Teach Learn, 11(12), 1287-1295.

https://doi.org/10.1016/j.cptl.2019.09.017

Woods, T. M., Acosta, W. R., Chung, E. P., Cox, A. G., Garcia, G. A., Klucken, J. R., et al. (2016). Academic Freedom Should Be Redefined: Point and Counterpoint. Am J Pharm Educ, 80(9), 146. https://doi.org/10.5688/ajpe809146 